\title{
A COMPARATIVE STUDY OF THE EFFECTS OF VARIOUS TREATMENTS ON THE CALCIUM AND PHOSPHORUS METABOLISM IN TETANY
}

\author{
I. Chronic Juvenile Tetany
}

By SHIH-HAO LIU

(From the Department of Medicine, Peking Union Medical Coilege, Peking, China)

(Received for publication November 1, 1927)

The problem of tetany has been of considerable interest to both clinicians and experimental workers. The variety of clinical conditions with which tetany is associated, and the divergent chemical findings in the blood which various types of tetany manifest, indicate that this condition is merely a clinical syndrome varying widely in etiology as well as in mechanism of production in the different types, although the final symptomatology may be identical. The importance of calcium in the pathogenesis of tetany has long been recognized (1). In infantile tetany (2), commonly occurring in children with rickets, there is a disturbance in the calcium metabolism with lowering of blood calcium. When a cure of tetany results, as from cod liver oil or ultraviolet radiation, the blood calcium rises. Similar disturbance in calcium metabolism takes place in tetany parathyreopriva (3), either experimental or following accidental removal of the parathyroid glands during thyroid operations. In gastric (4), bicarbonate (5), or hyperpneic tetany (6), however, the blood calcuum remains normal, while the bicarbonate of the blood is increased with a tendency toward an alkaline reaction. Freudenberg and György (7) in attempting to harmonize these discordant observations, state that the essential element in tetany is the concentration of ionized calcium in the blood. Rona and Takahashi (8) showed that the calcium ion concentration in the blood depends not only on the actual concentration of the total calcium, but also on the bicarbonate and hydrogen ion concentrations according to the following equation:

$$
\frac{\left(\mathrm{Ca}^{++}\right)\left(\mathrm{HCO}_{3}^{-}\right)}{\left(\mathrm{H}^{+}\right)}=\mathrm{K}
$$


Theoretically, an increase of bicarbonate ion concentration and a shift toward an alkaline reaction as occur in gastric, bicarbonate and hyperpneic tetany, tend to diminish the calcium ions in the blood and thereby cause the symptoms of tetany.

As there is at present no available method of directly measuring the calcium ion concentration in the blood, many attempts have been made to separate serum calcium into diffusible and non-diffusible portions, thus indirectly, perhaps incompletely, gaining an idea of the state of calcium in the blood. Different methods employed for the purpose have yielded different results as discussed in a recent paper on the subject (9). The overwhelming evidence seems to be in favor of the view that it is the diffusible rather than the non-diffusible calcium that is physiologically important in the control of neuro-muscular irritability and that it is the diffusible fraction that is decreased in tetany, although Cruickshank (10), and Cameron and Moorhouse (11) conclude that in tetany parathyreopriva the reduction in calcium is mainly in the non-diffusible fraction. Von Meysenbug and McCann (12), and Moritz (13) found that both the diffusible and non-diffusible calcium were reduced in the same ratio.

Recent experiments in the treatment of tetany have been made largely in the effort to throw light on the mechanism of its production. but the effects of various treatments have not been correlated and quantitatively compared. MacCallum and Voegtlin (1) found that immediate relief of symptoms from parathyroid tetany can be brought about by intravenous injections of soluble calcium salts, and emphasized the prime importance of sufficient calcium in the diet in order to maintain a normal neuro-muscular irritability. Acids and acidproducing substances, which are supposed to increase the ionization of calcium, have also been tried in the treatment of tetany. Gamble and Ross (14) administered hydrochloric acid, calcium chloride and ammonium chloride to children and showed that on their administration the carbon-dioxide capacity of the blood is decreased and the hydrogen ion concentration increased without necessarily affecting the total serum calcium level. The therapeutic effects of these substances are explained on the basis of increased ionization of calcium so that a physiologically adequate concentration of calcium ions is obtained, even though the total serum calcium may be low. 
Huldschinsky (15), Casparis and Kramer (16), and Hoag and his collaborators (17) have shown that ultraviolet radiation has remarkable effect in the treatment of infantile tetany and in raising the serum calcium, due probably to an increased absorption of calcium through the intestinal tract. Brown, MacLachlan and Simpson (18) treated seven cases of infantile tetany with equally good results. Liu (19), in studying the influence of cod liver oil on the calcium and phosphorus metabolism in tetany, found that cod liver oil, similar to ultraviolet radiation, increases the calcium retention and raises the blood calcium, thereby curing tetany.

With the advent of Collip's discovery (20) of a parathyroid extract active in raising the blood calcium of both normal and parathyroidectomized dogs, this treatment has been applied to human subjects. According to Greenwald and Gross (21) the injection of this extract increases the excretion of calcium both in the urine and feces in dogs. The co-existence of hypercalcemia and increased calcium output is taken to indicate that the parathyroid hormone mobilizes calcium from the tissues, chiefly the bones. In normal calves (22), the administration of parathyroid extract is followed by increased calcium and phosphorus excretion in the urine, but no consistent change in the feces. In the experiments of Stewart and Percival (23), it is demonstrated in cats that the main excretory route of calcium is the large intestine and that following the parathyroid extract injections, while the serum calcium remains elevated, there is no change in the excretion of calcium. Apparently there is considerable difference in opinion as to the mode of action of the parathyroid extract, partly on account of the different species of animals employed. The mode of action of this extract in man has not been definitely established, although its beneficial effects on parathyroid tetany (24) and infantile tetany (25) have been reported, and Hoag et al. (26) have obtained diminished calcium retention in one normal and three rachitic infants, and increased calcium retention in two cases of infantile tetany during the period of parathyroid extract administration.

The present communication has for its purpose the study and comparison of the effects of the various treatments on the calcium and phosphorus metabolism in two cases of chronic juvenile tetany, embodying the measurements of the intake and output of these ele- 
ments in conjunction with their blood levels and the partition of serum calcium into diffusible and non-diffusible portions.

\section{EXPERIMENTAL SUBJECTS}

The two subjects studied were girls, one aged 16, the other 17 , each showing on admission to the hospital marked carpopedal spasm, Chvostek's sign, Trousseau's sign, and increased electrical reaction typical of tetany. They gave a history of repeated attacks of the same nature every winter for the past three or four years, with complete remissions in the summer. They came from an orphanage near Peking, containing about 400 boys and 330 girls varying from 5 to 22 years of age. Investigation in January, 1927, revealed that 34 per cent of the girls and 22 per cent of the boys were affected with tetany of varying intensity from active symptoms and signs to only a positive facial phenomenon without complaints. This exceedingly high incidence of tetany in the orphanage suggests the operation of some factor or factors that are related to the diet or conditions of living of its inmates. Hammond and Hsia (27) have carefully studied their living conditions as well as their diet. They state that they are living a happy useful life, working hard and playing actively. Their diet, consisting chiefly of millet, wheat and corn meals, is monotonous, there being no change except occasional substitution of vegetables in season. According to their estimates, children of 16 take daily about 18 grams of fat, 57 grams of protein and 380 grams of carbohydrate, with a total intake of approximately 1900 calories. Thus the protein intake is moderately low, the fat intake very low, and the carbohydrate intake correspondingly high. By calculating from the diet lists, the daily average calcium intake is approximately 0.15 gram and phosphorus intake 0.5 gram. Shohl and Sato (28) suggest that the average calcium requirement is 0.0153 gram per kilo of body weight per day, or 0.6120 gram for a person of 40 kilos (one subject weighing 41 , the other 36 kilos). Ehrström (29) considers that the minimum of phosphorus required is 0.0261 gram per kilo per day, or 1.044 gram by a person of 40 kilos. According to these criteria, the intake of both calcium and phosphorus in the orphanage diet is very low. However, as shown presently, as well as from the seasonal incidence of tetany, calcium lack cannot be the sole cause of tetany in these cases. 


\section{METHOD OF INVESTIGATION}

The two subjects were placed in the metabolism ward where carefully weighed diets with constant calcium intake, and complete collection of both urine and stools were ensured. Urine was collected as 24-hour specimens, and stools were marked off with carmine to correspond to 4-day periods, 0.5 gram of the dye being given by mouth at the same time of the day every four days. Calcium and phosphorus in urine were determined daily, and those in stools every four days. Throughout the experimental period they were on a diet with a constant daily intake of calcium, which was only slightly higher than the estimated value from their previous diets in the orphanage. The calcium and phosphorus values of some of the foods were taken from Sherman (30), and others obtained from analyses made in the laboratory of Dr. Hsien Wu of the Peking Union Medical College. Four varieties of treatments were given, namely, $(a)$ hydrochloric acid, 10 per cent, from $4 \mathrm{cc}$. to $12 \mathrm{cc}$. daily, (b) calcium chloride, 20 per cent solution, $5 \mathrm{cc}$. twice a day, corresponding to $\mathbf{2}$ grams of calcium chloride, or $\mathbf{0 . 7 2 2}$ gram of calcium daily, $(c)$ pure cod liver oil in $30 \mathrm{cc}$. daily doses, and (d) parathyroid extract (Collip) subcutaneously, 25 to 100 units daily, usually given in two injections. Each kind of treatment was given for two or three periods of four days each with one or two control periods before and after the treatment. Blood was always withdrawn before the noon meal from one of the arm veins, and estimated for calcium, phosphorus, chloride and carbon-dioxide capacity as well as for partition of serum calcium into diffusible and non-diffusible fractions.

Blood calcium was determined by the method of Tisdall as modified by Clark and Collip (31), phosphorus by that of Benedict (32). The method of Myers and Short (33) was employed for blood chloride and that of Van Slyke and Cullen (34) for carbon-dioxide capacity. The partition of serum calcium was studied with the method of Moritz (13), modified by Updegraff, Greenberg and Clark (35), and the diffused and non-diffused calcium were separately determined. Briggs' method (36) was used for urinary phosphorus and Shohl and Pedley's method for urinary calcium. The stools of each 4-day period were mixed, dried in an oven at about $110^{\circ} \mathrm{C}$. to a constant weight, and ground into a fine powder. Exactly 2 grams of the dried stool were weighed in a platinum crucible and ashed to a whitish powder. The ash was dissolved in $0.1 \mathrm{~N}$ hydrochloric acid, and an aliquot portion taken for analysis of calcium and phosphorus. The calcium was determined by Clark and Collip's method (31) with the addition of $1 \mathrm{cc}$. of 20 per cent sodium acetate in the initial precipitation, and phosphorus by Briggs' method (36).

\section{REPORT OF CASES}

Case I. Hospital No. 15846. T. C. C., a Chinese girl of 16 , was admitted to the Peking Union Medical College Hospital on January 19, 1927, for repeated attacks of numbness and spasm of hands and feet lasting about a month. For three years previously, she had had similar spasticity of hands and feet during the 
colder months, disappearing toward the end of spring. The attacks varied in severity from transient stiffness of fingers to painful spasm of hands and feet with twitching of facial muscles and difficulty in articulation for several days. Exposure to cold and emotional disturbances on several occasions seemed to precipitate the attacks.

On examination, the patient was well nourished and well developed. Weight $36 \mathrm{~kg}$., height $145 \mathrm{~cm}$. She was apparently suffering from pain in her hands and feet, which assumed the typical positions of carpopedal spasm. Both Trousseau's sign and the facial phenomenon were strongly positive. Galvanic electrical reaction showed hyperexcitability, a cathodal closing contraction being obtained with only 0.3 milliampères with the ulnar nerve. Roentgenogram showed no change in the structure of the pelvic bones. Serum calcium was $6 \mathrm{mgm}$. with 3.3 mgm. of diffusible and $3.2 \mathrm{mgm}$. of non-diffusible calcium, phosphorus $5.88 \mathrm{mgm}$. and sodium chloride $619 \mathrm{mgm}$. per $100 \mathrm{cc}$, and carbon-dioxide combining power 53.8 volume per cent.

After admission, the patient was put on a diet with a calcium intake of 0.18 to 0.20 gram daily, an intake slightly higher than that in the orphanage diet which she had been eating for several years. During the control period of four days, spasms of the hands continued. Then four consecutive periods of four days each were devoted to acid treatment. Following the administration of hydrochloric acid, she felt gradually improved with relief of spasms and at the end of the third period her blood calcium rose to $8.5 \mathrm{mgm}$. with $5.8 \mathrm{mgm}$. of diffusible and $3.2 \mathrm{mgm}$. of non-diffusible calcium (table 1 and chart 1). But with further administration of hydrochloric acid, the blood calcium fell to the original level coinciding with the reappearance of tetany. With the ingestion of acid, an increased calcium excretion occurred both in the urine and feces with the result that the calcium balance, distinctly positive during the control period, became negative and increasingly so with further acid ingestion.

During the two periods of parathyroid extract administration, the relief of tetany was complete and more prompt than the acid periods, both Trousseau's and Chvostek's signs being negative within the third day of the injections. The patient's blood calcium rose from 6.5 to $9.0 \mathrm{mgm}$., $5.6 \mathrm{mgm}$. diffusible and $3.4 \mathrm{mgm}$. non-diffusible. In regard to the calcium balance, there was slightly more retention of calcium during the parathyroid extract periods than in the immediately preceding and following control periods. The effect of the extract, 


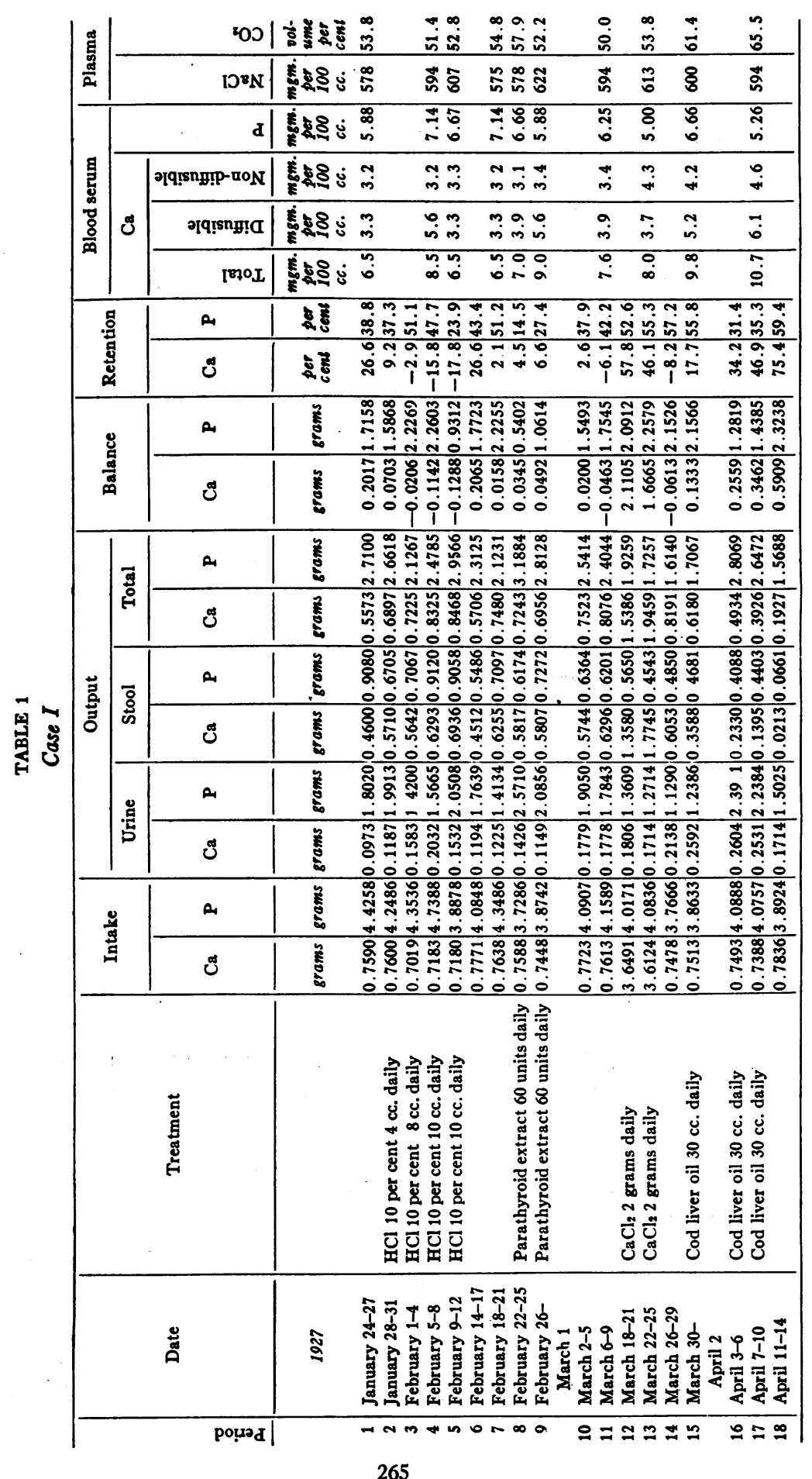

THE JOURNAL OF CLINICAL INVESTigation, vol. v, No. 2 
however, did not last, and the signs of tetany recurred three or four days after the discontinuation of the treatment.

For two periods calcium chloride was then given in 2 grams daily doses corresponding to a four-fold increase of the intake of calcium. The striking result was a large retention of calcium, amounting to 2.11 grams or 57.8 per cent during the first period and 1.67 gram or 46.1 per cent during the second. But the blood calcium was essen-

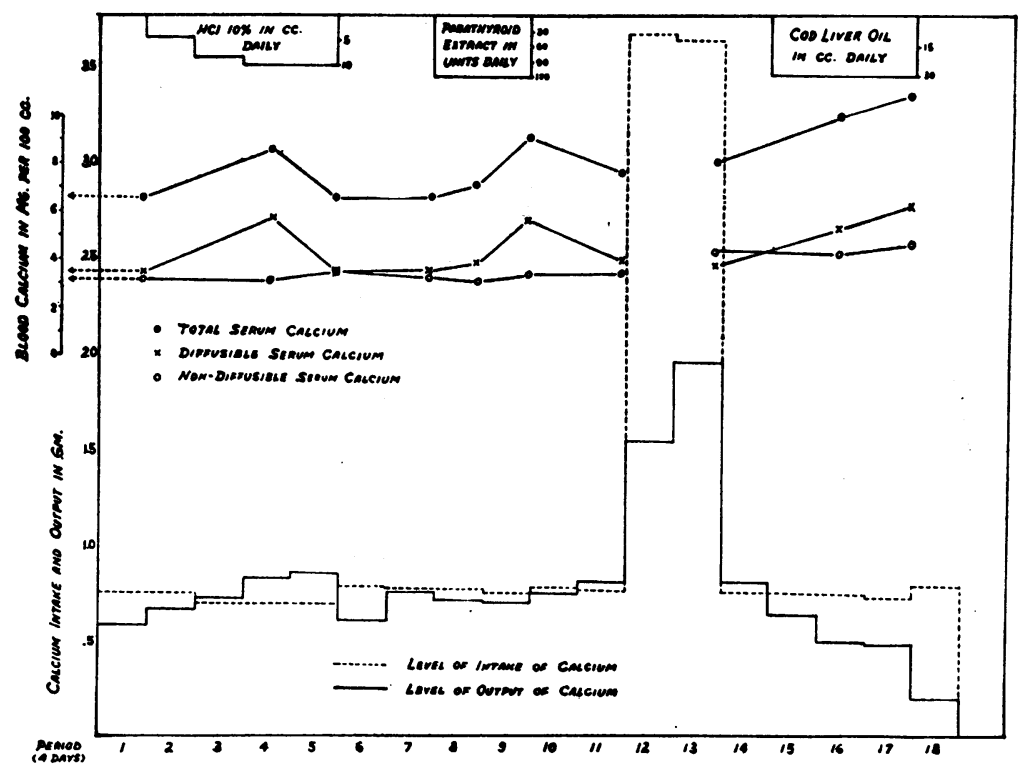

Chart 1. Case I. The Efrect of Various Treatments on the Calcium Balance, and the Total, Diffusible and Non-Difrusible Serum Calcium

tially unchanged. There was no improvement whatsoever in the signs and symptoms.

The last treatment, namely, cod liver oil, seemed to be the most satisfactory. Three consecutive periods were devoted to this treatment. The relief of tetany was as complete and prompt as during the parathyroid extract period, but more permanent. Blood calcium was raised from 8.0 to $10.7 \mathrm{mgm}$., the increase occurring chiefly in the 
diffusible portion. Calcium was retained in increasingly greater amounts, and the retention of calcium seemed to be due to a reduction in its fecal excretion, as its elimination in the urine was slightly increased during the cod liver oil periods. The effect of cod liver oil remained long after the treatment was stopped. She was discharged well on April 18, 1927.

Case II. Hospital No. 12947. L. H. T., a Chinese girl, aged 17, was admitted to the Peking Union Medical College Hospital on January 11, 1927, complaining of tonic spasm of fingers, hands, toes and feet for about two weeks. Two years before, during winter months, she noticed numbness and stiffness of fingers, and with the onset of warmer months, she became symptom-free. A year ago, she entered the hoispital for the same trouble with typical signs of tetany. Her condition improved after ultraviolet radiation, serum calcium being raised from 8.5 to $9.7 \mathrm{mgm}$. She remained well until shortly before the present admission when a recurrence of tetany took place with spastic attacks of hands and feet more severe than before.

She was well nourished but slightly undersized. Weight $41 \mathrm{kgm}$., height 142 $\mathrm{cm}$. Physical examination was essentially negative except for the presence of the classical signs of tetany. She was not in an acute attack, but both Chvostek's sign and Trousseau's sign were positive and the electrical reaction showed hyperirritability. Serum calcium was $8.8 \mathrm{mgm}$. per $100 \mathrm{cc}$. with $3.3 \mathrm{mgm}$. diffusible and $5.5 \mathrm{mgm}$. non-diffusible, phosphorus $3.12 \mathrm{mgm}$., sodium chloride $584 \mathrm{mgm}$., and carbon-dioxide capacity 67.2 per cent.

The patient was put on a diet similar to that of case I, and her first treatment was a series of parathyroid extract injections, 60 units daily for two periods. Her blood calcium rose from 8.8 to $9.7 \mathrm{mgm}$., the rise being entirely in the diffusible fraction (table 2, chart 2). The retention of calcium increased slightly during the parathyroid extract periods. With the elevation of blood calcium to almost normal level, especially the diffusible calcium, as well as the increase in calcium retention, her symptoms were entirely relieved, with disappearance of both Chvostek's and Trousseau's signs.

After a rest period of four days, during which her symptoms returned, she was given hydrochloric acid for two periods. With the acid administration, she experienced no relief whatsoever. Her serum calcium dropped from 8.4 to $7.7 \mathrm{mgm}$. The calcium balance, positive previously and during the first acid period, became negative during the second acid period with an increased excretion of calcium both in the urine and feces. 


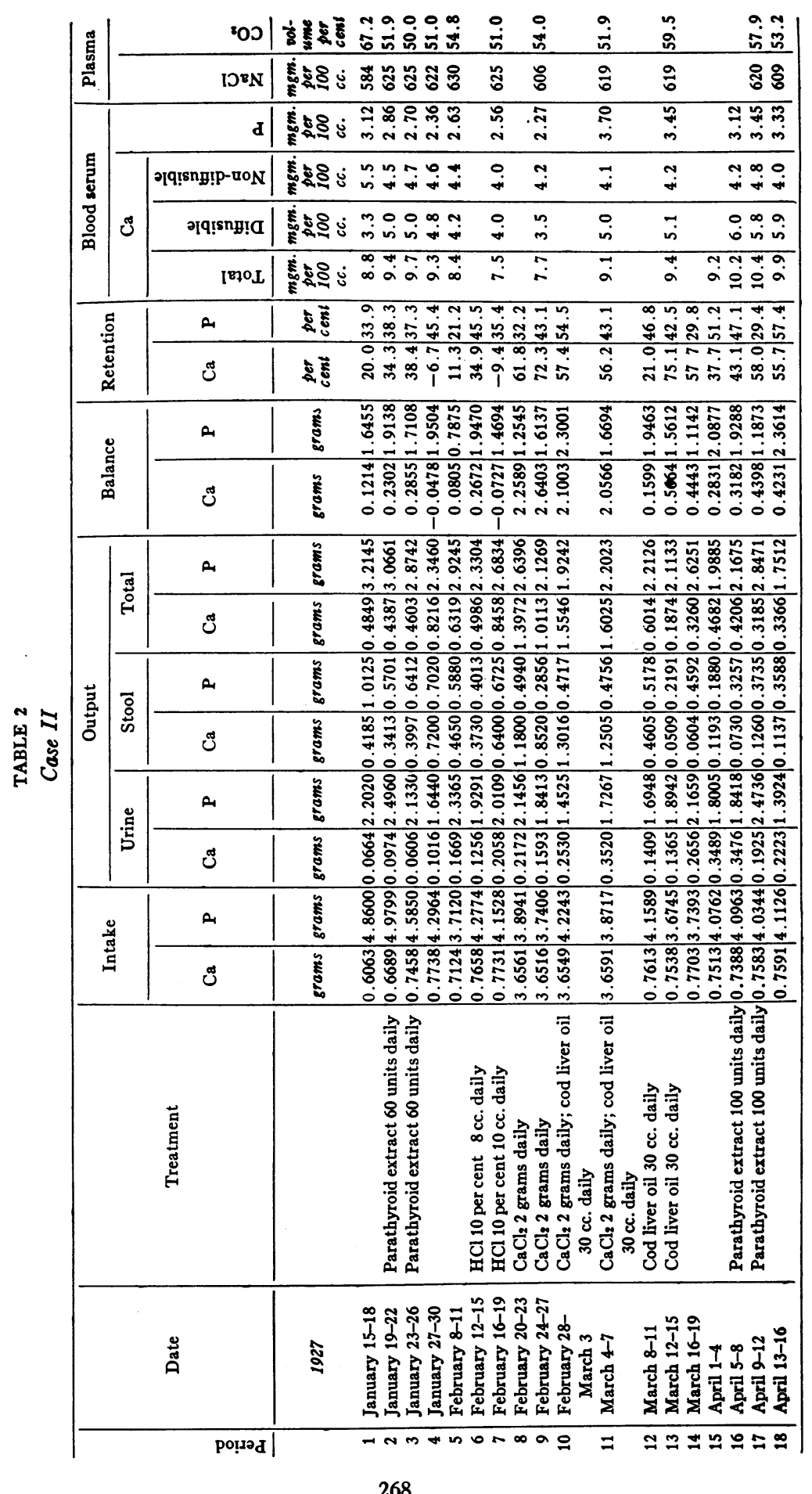


Calcium chloride, 2 grams daily, was given alone for two periods, and then combined with cod liver oil $30 \mathrm{cc}$. daily for another two periods. During the first two periods when calcium chloride alone was given, the treatment made no apparent difference to her symptoms and her blood calcium remained stationary, although there was a large retention of calcium. But during the second two periods when cod liver oil was added to calcium chloride, her blood calcium rose from 7.7 to $9.1 \mathrm{mgm}$. with $5.0 \mathrm{mgm}$. of diffusible calcium, coinciding with

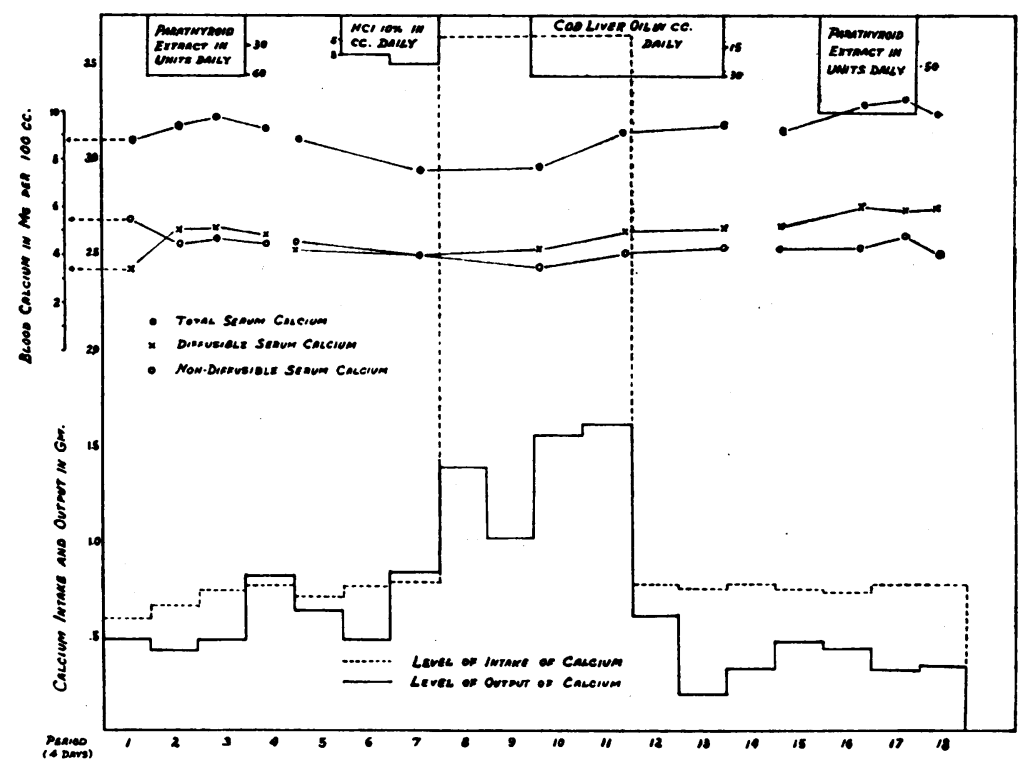

Chart 2. Case II. The Effect of Various Treatments on the Catctum Balance, and the Total, Diffusible and Non-Diffusible Serum Calctum

the disappearance of tetany. There was, however, no further increase in the retention of calcium with the aid of cod liver oil.

During the next two periods when cod liver oil alone was continued, her blood calcium continued to rise slightly. The striking change was the tremendous increase in the retention of calcium, amounting to 75 per cent of the calcium in the diet. This effect continued during the succeeding periods when cod liver oil was stopped. 
Toward the end of the experimental period, when she was remaining free from symptoms, another course of parathyroid extract injections was given, 100 units daily for two periods. There was a slight increase in the blood calcium, namely, to $10.4 \mathrm{mgm}$. with $58 \mathrm{mgm}$. of diffusible calcium. The calcium output was decreased slightly resulting in a better retention than the control periods. The patient was discharged well on April 18, 1927.

\section{DISCUSSION}

It has been shown (9) that in normal individuals the total serum calcium of about $10 \mathrm{mgm}$. per $100 \mathrm{cc}$. is divided equally between the diffusible and the non-diffusible fractions. In case I with a total calcium of $6.6 \mathrm{mgm}$., there was a proportionate decrease in both fractions, while in case II, in whom the total calcium was slightly low (8.8 $\mathrm{mgm}$.), the reduction was mainly in the diffusible portion (3.3 mgm.), the non-diffusible portion remaining normal. It is apparently the reduction of the diffusible calcium that is associated with the appearance of tetany, regardless of the level of the total calcium. This is further substantiated by the fact that in nephrosis and kalaazar (9) the' low total calcium which in these conditions is due to a reduction of non-diffusible calcium alone, is not accompanied by neuro-muscular irritability. When the blood calcium was raised with accompanying clinical improvement in these two cases as by cod liver oil or parathyroid extract, the rise was more marked in the diffusible than in the non-diffusible fraction, again emphasizing the prime importance of the diffusible calcium in maintaining a normal neuromuscular irritability.

From the metabolism data presented, the comparative efficacy of the various treatments in tetany is obvious. The administration of hydrochloric acid in this form of tetany does not seem to be a rational therapeutic procedure. In case I, there was a transient increase of blood calcium with slight relief of symptoms, but a negative balance of calcium was obtained with increased excretion of calcium both in the urine and feces. With further use of the acid, the blood calcium went back to the original level with reappearance of tetany, and the calcium loss was increased. Hydrochloric acid seems to possess a depleting influence on the calcium stores of the body. Case II showed no con- 
sistent response to the acid treatment. Although there was no actual calcium loss from the body, the blood calcium was slightly decreased. Thus the acid administration may or may not raise the blood calcium, and has a tendency to increase the excretion of calcium.

Merely increasing the intake of calcium did not raise the blood calcium nor relieve the symptoms in either case. Various authors attribute the failure to the lack of absorption from the intestines, but this does not seem borne out by the data presented, as the retention of calcium during the periods of calcium chloride administration is both absolutely and relatively greater than the control periods, thus showing good absorption. Apparently it is not absorption alone that controls the level of blood calcium, and there must be some other factor that keeps the absorbed calcium in the blood so as to be available for the maintenance of normal excitability of the nerves. This active factor seems to reside in both cod liver oil and parathyroid extract. The potent parathyroid extract, as these two cases exhibit, promptly increases the blood calcium to normal levels with complete relief of symptoms. There was no increased excretion of calcium either in the feces or urine, contrary to the findings of Greenwald and Gross (21) with experiments in dogs. In fact there was a tendency to increased calcium retention in both cases, especially in case II. This is in agreement with the results of Hoag et al. (26) in the treatment of two cases of infantile tetany. The prompt and marked action on the blood calcium without extensively affecting the calcium balance indicates that the main function of the parathyroid hormone seems to be the control of the distribution of calcium between the blood and tissues rather than the regulation of the rate of excretion or absorption. This substantiates the work of Stewart and Percival (23).

Cod liver oil seems to be efficacious both in raising the blood calcium and in increasing the calcium retention. In both cases, the blood calcium was promptly and markedly increased with the administration of cod liver oil. The increase in the retention of calcium was also very pronounced, more so when the calcium intake was restricted, as no further increase in calcium retention could be brought about with the aid of cod liver oil when calcium intake was already in excess, as in case II. Thus besides controlling the level of blood calcium, cod liver oil increases the positive calcium balance. Examination of the 
output of calcium in urine and feces during the cod liver oil periods shows that the fecal output is greatly decreased, while the urinary output remains stationary or slightly increased, suggesting that cod liver oil acts on the intestines, either increasing the absorption or decreasing the elimination, probably the former.

With regard to phosphorus metabolism the results are less regular and less conclusive. Hydrochloric acid seems to increase the retention of phosphorus, and the decreased phosphorus output is probably the result of the increased chloride available for excretion. Similarly, calcium chloride increases the phosphorus retention, though not so markedly as in the case of hydrochloric acid. Parathyroid extract gives no consistent results on the phosphorus balance, nor does cod liver oil.

The changes in the blood, other than those of calcium, are slight and inconstant.

We may add a word about the pathogenesis of the type of tetany which occurs in the orphanage concerned. The clinical features, the seasonal incidence and the favorable response to cod liver oil therapy as well as to ultra-violet radiation in case II during her first admission, justify its classification as infantile tetany. As stated in the beginning, the calcium intake in the orphanage diet is decidedly deficient, and, as shown by the metabolic data during the preliminary periods, the calcium retention is also very low. But the restricted intake and poor retention cannot be the only factors responsible for the occurrence of tetany, as the administration of large quantities of calcium fails to relieve the symptoms or raise the blood calcium, although the calcium given is absorbed and retained with avidity. There must be an additional, perhaps more important factor that regulates the distribution of calcium between the blood and tissues. Parathyroid extract is potent in this respect. But these cases do not behave as cases of tetany resulting from loss of parathyroid glands, and the peculiar seasonal variation speaks against a deficiency of parathyroid action, which would be more or less continuous.

Cod liver oil (or the active principle therein contained) is also very active in raising blood calcium, and in increasing the retention of calcium, especially when the intake is limited. But if it were a case of deficiency in cod liver oil or its active principle as is quite possible 
in view of the monotonous, low-fat containing diet, the seasonal incidence again would require explanation. When the fact that the incidence of tetany varies with the intensity of the ultraviolet ray in the solar spectrum is considered, may it not be likely that the ultraviolet ray being more intense in the summer is sufficient to make up for whatever is deficient; but becomes quite ineffective in the winter? However further work seems necessary along this line.

\section{SUMMARY AND CONCLUSIONS}

1. Two of a large series of cases of tetany resembling infantile tetany occurring in an orphanage are studied with respect to the effects of various treatments on the calcium and phosphorus metabolism.

2. Merely increasing the intake of calcium does not relieve the symptoms nor raise the blood calcium, although 50 to 60 per cent of the intake may be retained.

3. Hydrochloric acid gave a transient rise of blood calcium with slight relief of symptoms in one case, but failed to do so in the other case. It tended to deplete calcium from the body stores.

4. The rise of blood calcium with relief of symptoms following parathyroid extract injections is prompt and marked. There is no increased excretion of calcium either in the urine or feces. In fact, the retention of calcium tends to increase slightly.

5. The effect of cod liver oil is similar to that of parathyroid extract, but more lasting. In addition there is a marked increase in the retention of calcium, especially when the calcium intake is limited. It seems to be the most efficient treatment in this type of tetany.

\section{BIBLIOGRAPHY}

1. MacCallum, W. G., and Voegtlin, C., J. Exper. Med., 1909, xi, 118. On the Relation of Tetany to the Parathyroid Glands and to Calcium Metabolism.

2. Howland, J., and Kramer, B., Monatschr. f. Kinderh., 1923, xxv, 279. A Study of the Calcium and Inorganic Phosphorus of the Serum in Relation to Rickets and Tetany.

3. Salvesen, H. A., J. Biol. Chem., 1923, lvi, 443. The Function of the Parathyroids.

4. McCann, W. S., J. Biol. Chem., 1918, xxxv, 553. A Study of the Carbondioxide Combining Power of the Blood Plasma in Experimental Tetany.

Youmans, J. B., and Greene, I. W., J. Am. Med. Assoc., 1925, lxxxiv, 808. Gastric Tetany; Report of a Case Treated with Ammonium Chlorid. 
5. Howland, J., and Marriott, W. McK., Quart. J. Med., 1918, xi, 289. Observations upon the Calcium Content of the Blood in Infantile Tetany and upon the Effect of Treatment by Calcium.

Harrop, G. A. Jr., Bull. Johns Hopkins Hosp., 1919, xxx, 62, Production of Tetany by the Intravenous Infusion of Sodium Bicarbonate.

Healy, W. P., Am. J. Obst. and Gynec., 1921, ii, 164. Post-operative Tetany Due to Sodium Bicarbonate.

Denis, W. and von Meysenbug, L., with the assistance of Goddard, J., J. Biol. Chem., 1923, lvii, 47. Alkalosis Versus Abnormal Sodium Ion Concentration as Cause of Tetany.

6. Collip, J. B., and Backus, P. L., Am. J. Physiol., 1920, li, 568. The Effect of Prolonged Hyperpnea on the Carbon-dioxide Combining Power of the Plasma, the Carbon-dioxide Tension of Alveolar Air and the Excretion of Acid and Basic Phosphate and Ammonia by the Kidney.

Grant, S. B., and Goldman, A., Am. J. Physiol., 1920, lii, 209. A Study of Forced Respiration: Experimental Production of Tetany.

Goldman, A., J. Am. Med. Assoc., 1922, Ixxviii, 1193. Clinical Tetany by Forced Respiration.

Barker, L. F., and Sprunt, T. P., Endocrinology, 1922, vi, 1. A Spontaneous Attack of Tetany During a Paroxysm of Hyperpnea in a Psychoneurotic Patient Convalescent from Encephalitis.

7. Freudenberg, E., and György, P., Jahrb. f. Kinderh., 1921, xcvi, 3 f. xlvi, 5. Zur Pathogenese der Tetanie.

8. Rona, P., and Takahashi, D., Biochem. Ztschr., 1913, xlix, 370. Beitrag zur Frage nach dem Verhalten des Calciums im Serum.

9. Liu, S. H., Chinese J. Physiol., 1927, i, 331. The Partition of Serum Calcium into Diffusible and Non-diffusible Portions.

10. Cruickshank, E. W. H., Brit. J. Exper. Path., 1923, iv, 213. Studies in Experimental Tetany; Distribution of Calcium, Colloidal and Ionic Calcium.

11. Cameron, A. T., and Moorhouse, V. H. K., J. Biol. Chem., 1925, lxiii, 687. Tetany of Parathyroid Deficiency and the Calcium of the Blood and Cerebro-Spinal Fluid.

12. Von Meysenbug, L., and McCann, G. F., J. Biol. Chem., 1921, xlvii, 541. The Diffusible Calcium of the Blood Serum; II. Human Rickets and Experimental Dog Tetany.

13. Moritz, A. R., J. Biol. Chem., 1925, lxiv, 81. The Effect of Ultraviolet Radiation on the State of the Serum Calcium.

14. Gamble, J. L., and Ross, G. S., Am. J. Dis. Child., 1923, xxv, 470 . Studies of Tetany. II. The Effect of Ingestion of Hydrochloric Acid Producing Substances on the Acid-Base Metabolism of an Infant, and the Probable Manner of Their Action in the Treatment of Tetany.

15. Huldschinsky, K., Ztschr. f. Kinderh., 1920, xxvi, 207. Die Beeinflussung der Tetanie durch Ultraviolettlicht. 
16. Casparis, H., and Kramer, B., Bull. Johns Hopkins Hosp., 1923, xxxiv, 219. The Treatment of Active Infantile Tetany with Radiations from Mercury Vapor Quartz lamp.

17. Hoag, L. A., Am. J. Dis. Child., 1923, xxvi, 186. Treatment of Infantile Tetany with Ultraviolet Radiation. Its Effect on the Clinical Symptoms and on the Calcium Concentration in the Blood Serum.

18. Brown, A., MacLachlan, I. F., and Simpson, R., Am. J. Dis. Child., 1920, xix, 413. The Effect of Intravenous Injections of Calcium in Tetany and the Influence of Cod Liver Oil and Phosphorus in the Retention of Calcium in the Blood..

19. Liu, S. H., China Med. J., 1924, xxxviii, 793. The Influence of Cod Liver Oil on the Calcium and Phosphorus Metabolism in Tetany.

20. Collip, J. B., J. Biol. Chem., 1925, 1xiii, 395. The Extraction of a Parathyroid Hormone Which Will Prevent or Control Parathyroid Tetany and Which Regulates the Level of Blood Calcium.

21. Greenwald, I., and Gross, J., J. Biol. Chem., 1926, lxviii, 325. The Effect of Long Continued Administration of Parathyroid Extract upon the Excretion of Phosphorus and Calcium.

22. Robinson, C. S., Huffmann, C. F., and Burt, K. L., J. Biol. Chem., 1927, lxxiii, 477. The Effect of the Administration of Parathyroid Extract on Normal Calves.

23. Stewart, C. P., and Percival, G. H., Biochem. J., 1927, xxi, 301. Studies on Calcium Metabolism. I. The Action of the Parathyroid Hormone on the Calcium Content of the Serum and on the Absorption and Excretion of Calcium.

24. Snell, A. M., J. Am. Med. Assoc., 1925, lxxxv, 1632. Parathyroid Extract in the Treatment of a Case of Tetany.

Monteith, J. R., and Cameron, A. T., Canad. Med. Assoc. J., 1926, xvi, 1104. A Case of Sub-Parathyroid Tetany Treated with Collip's Extract of Parathyroid.

25. Collip, J. B., and Leitch, D. B., Canad. Med. Assoc., J., 1925, xv, 59. A Case of Tetany Treated with Parathyrin.

26. Hoag, L. A., Rivkin, H., Weigele, C. E., and Berliner, F., Am. J. Dis. Child., 1927, xxxiii, 910. Effect of Potent Parathyroid Extract on Calcium Balance in Infants.

27. Hammond, J., and Hsia Sheng, Am. J. Dis. Child., 1925, xxix, 729. The Development and Diet of Chinese Children.

28. Shohl, A. T., and Sato, A., J. Biol. Chem., 1923-24, lviii, 257. Acid-Base Metabolism. II. Mineral Metabolism.

29. Ehrström, R., Skand. Arch. Physiol., 1903, xiv, 82. Zur Kenntnis der Phosphorumsatzes bei dem erwachsenen Menschen. Quoted from Von Noorden, C., Metabolism, London, 1907, i, 422.

30. Sherman, H. C., Chemistry of Nutrition, New York, 1924, 421. 
31. Clark, E. P., and Collip, J. B., J. Biol. Chem., 1925, lxiii, 461. A Study of the Tisdall Method for the Determination of Blood Serum Calcium with a Suggested Modification.

32. Benedict, S. R., and Theis, R. C., J. Biol. Chem., 1924, Ixi, 63. A Modification of the Molybdic Method for the Determination of Inorganic Phosphorus in Serum.

33. Myers, V. C., and Short, J. J., J. Biol. Chem., 1920, xliv, 47. The Estimation of Chlorides in Blood.

34. Van Slyke, D. D., and Cullen, G. E., J. Biol. Chem., 1917, $x x x, 289$. Studies of Acidosis. I. The Bicarbonate Concentration of the Blood Plasma, its Significance and its Determination as a Measure of Acidosis.

35. Updegraff, H., Greenberg, D. M., and Clark, G. W., J. Biol. Chem., 1926-27, lxxi, 86. A Study of the Distribution of the Diffusible and Non-Diffusible Calcium in the Blood Sera of Normal Animals.

36. Briggs, A. P., J. Biol. Chem., 1922, liii, 13. A Modification of the BellDoisy Phosphate Method.

37. Shohl, A. T., and Pedley, F. G., J. Biol. Chem., 1922, 1, 537. A Rapid and Accurate Method for Calcium in Urine. 